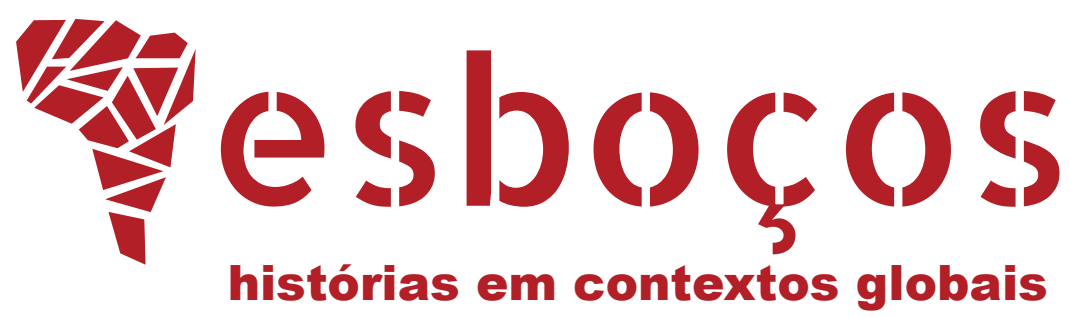

\title{
PARCEIROS EM QUÊ? A ALIANÇA \\ PARA O PROGRESSO E A POLÍTICA \\ EDITORIAL DE MODERNIZAÇÃO DA \\ AMÉRICA LATINA NO CONTEXTO DA GUERRA FRIA
}

Partners in What? The Alliance for Progress and the Editorial Policies for Modernizing Latin America in the Cold War Era

Rafael R. Ioris ${ }^{a}$

(D) https://orcid.org/0000-0003-1956-2698 E-mail: rafael.ioris@du.edu

Josiane Mozer ${ }^{b}$

(1) https://orcid.org/0000-0002-1251-8566 E-mail: josiane.mozer@ymail.com

a University of Denver, History Department and Latin American Center, Josef Korbel School of International Studies, Denver, CO, Estados Unidos

b Universidade Federal do Rio Grande do Sul, Instituto de Filosofia e Ciências Humanas, Departamento de História, Porto Alegre, RS, Brasil 


\title{
RESUMO
}

A Aliança para o Progresso, política elaborada pelo governo Kennedy, no início dos anos 1960, com fins de promover o desenvolvimento nos moldes capitalistas na América Latina, assentava-se sob um dilema de difícil conciliação. Por um lado, as demandas da região por desenvolvimento econômico não poderiam mais ser ignoradas; por outro, percebia que um desenvolvimento autônomo da América Latina, nos moldes idealizados pela Aliança, poderia levar a uma diminuição da influência regional dos Estados Unidos. Entre as pressões dos países latino-americanos e os interesses hegemônicos dos Estados Unidos, a Aliança foi rapidamente assumindo contornos coercitivos e ideológicos, esvaziando de sentido a proposta de parceria para o bem comum. Baseando-se em documentação produzida pelo Departamento de Estado e pela Agência de Informação dos Estados Unidos (USIA), o presente artigo tem por objetivo tratar da ação ideológica da Aliança para o Progresso. O foco da reflexão apresentada se centra na análise da política editorial implementada ao longo dos anos 1960, que buscava influenciar os debates sobre desenvolvimentismo travados no Brasil e na América Latina e, assim, promover a defesa de um capitalismo adequado à hegemonia estadunidense. A análise demonstra que, apesar de inovadora e ambiciosa como política externa hemisférica, a implementação da Aliança foi permeada por continuidades ideológicas e preocupações geopolíticas tradicionais do relacionamento dos Estados Unidos com a região latino-americana.

\section{PALAVRAS-CHAVE}

Guerra Fria. Aliança para o Progresso. USIA.

\begin{abstract}
The Alliance for Progress, program devised by the Kennedy administration early in the 1960s, aimed at promoting regional development of Latin America along US-like capitalist lines, was mired in an inherent contradiction. On the one hand, the program acknowledged that the US could no longer ignore Latin American demands for development. On the other, it realized that its autonomous development, according to the model idealized by the Alliance, could reduce the influence of the United States in the region. In the interplay of Latin American pressures and hegemonic interests of the United States, the Alliance assumed coercive and ideological contours, rendering the partnership for common good meaningless. Grounded on primary documentation produced by the State Department and the US Information Agency (USIA), the present article examines the ideological action of the Alliance for Progress. The focus of the reflection is centered on the analysis of editorial policies implemented along the 1960s, which aimed at influencing debates on the development that took place in Brazil and Latin America so to promote capitalism appropriate to American hegemony. The analysis demonstrates that, in spite of being an innovative and ambitious external policy, the implementation of the Alliance was mired in ideological continuities and geopolitical concerns traditionally shaping the relation between the United States and Latin America.
\end{abstract}

\section{KEYWORDS}

Cold War. Alliance for Progress. USIA. 


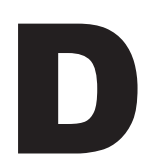
esde a postulação da Doutrina Monroe, no primeiro quarto do século XIX, até a implementação da Política de Boa Vizinhança, nos anos 1930, os Estados Unidos buscaram exercer, de forma continuada, sempre paternalista e muitas vezes violenta, seu domínio econômico, preponderância político-diplomática e influência cultural e ideológica no hemisfério ocidental. No pós-Segunda Guerra, esse padrão de comportamento adquiriu um novo formato, mais coordenado e multifacetado a partir de 1961. De fato, ainda que, ao longo dos primeiros quinze anos da Guerra Fria, a América Latina não tenha sido considerada prioridade das políticas hegemônicas estadunidenses, desde a Revolução Cubana, os líderes ianques finalmente entenderam que as demandas por desenvolvimento econômico apresentadas pelos países latino-americanos exigiam novas iniciativas por parte do hegemon hemisférico, a fim de que seus interesses na região pudessem ser defendidos.

Orientado por uma importante mudança de percepção sobre o papel dos Estados Unidos no continente, que já fora iniciada nos últimos anos do governo Eisenhower, com a criação do Banco Interamericano de Desenvolvimento (BID) e as negociações em torno da Operação Pan-Americana, Kennedy assume o governo determinado a inovar. Seu primeiro passo, já no segundo mês de mandato, foi anunciar às delegações latino-americanas em Washington a formulação de um amplo conjunto de políticas e programas, apresentado sob o sugestivo rótulo de uma Aliança para o Progresso (AFP, na sigla em inglês).

Em que pesem seus resultados controversos e discutíveis, a AFP foi até hoje a mais abrangente e ambiciosa iniciativa diplomática de cunho multilateral formulada pelos Estados Unidos para a América Latina, superando, no escopo e nos objetivos específicos, o aprofundamento das relações comerciais entre o país e a região sob a Política da Boa Vizinhança. Paradoxalmente, ao reagir de maneira tão determinada ao movimento revolucionário de Cuba e, aos poucos, empurrá-la para o isolamento regional e a consequente aproximação com a União Soviética, os Estados Unidos, a um só tempo, trouxeram para dentro do continente os embates diretos da Guerra Fria e as estratégias de contenção ao "inimigo interno".

Apesar dos objetivos formais declarados na Carta de Punta del Leste, em agosto de 1961, e da adesão de quase todos os países latino-americanos, a implementação do programa foi marcada por impasses burocráticos e pela falta de um genuíno compromisso por reformas estruturais nas sociedades latino-americanas, tanto por parte dos Estados Unidos quanto por parte de segmentos sociopolíticos dos países da região. O programa se revelou, muitas vezes, uma política muito mais comprometida com o fluxo de capital estadunidense do que com o avanço socioeconômico que retoricamente defendia para os países da região. Assim, ao fim e ao cabo da década de 1960, o registro histórico do programa foi permeado por expectativas recíprocas frustradas, ressentimento mútuo e oportunidades perdidas de cursos de ação mais sustentáveis e construtivos entre as nações do hemisfério (ROGES, 1967; SCHEMAN, 1988; SCHLESINGER, 2002).

O Brasil, visto desde o início como país-chave para o sucesso do novo programa, foi receptor da maior quantidade de recursos, de um ponto de vista absoluto. Mas, de maneira similar ao que ocorreu com o programa em nível regional, e ao contrário da maioria das expectativas, a implementação da Aliança no Brasil aprofundou o antagonismo político, abrindo caminho para o golpe civil-militar de 1964 e para a consolidação de um projeto desenvolvimentista liberal fortemente ancorado na lógica e em interesses do capital privado estadunidense. 
Focado nas experiências da AFP, mas avançando de modo a incorporar o contexto mais amplo das relações ligadas à temática do desenvolvimento regional travadas entre Washington e a América Latina, em especial com o Brasil no âmbito da Guerra Fria, este artigo analisará a ação ideológica ${ }^{1}$ exercida pelos Estados Unidos por meio de uma ampla e diversificada política editorial. Tal política, interessada e ideológica, se realiza numa totalidade socialmente construída e regida por um modo específico de produção - a capitalista -, permeada pelo antagonismo das classes que disputam, no campo das ideias, a construção de consenso para a hegemonia política. Assim será compreendida, neste artigo, a política editorial planejada e executada por diferentes agências e atores norte-americanos para influenciar ideologicamente a produção e a circulação de conhecimento durante a Guerra Fria, que ganhou contornos específicos sob a AFP. ${ }^{2}$

Oartigo inicia com uma revisão breve sobre as especificidades do relacionamento entre Brasil e Estados Unidos no contexto do lançamento e dos primeiros anos da AFP. Com base nessa análise, apresentamos a seguir apontamentos centrais sobre o papel da diplomacia pública na política externa de Washington, sobretudo por meio da atuação de sua agência de informação, a USIA. Por fim, analisamos a política editorial estadunidense e seu papel sob a AFP. Como um todo, buscamos argumentar ao longo das seguintes linhas que, apesar dos novos e apurados meios de promoção de um ideário político e econômico fundado nos valores liberais do desenvolvimento capitalista, a atuação dos Estados Unidos no contexto latino-americano continuou a ser fortemente marcada por interesses estratégicos e vieses ideológicos típicos da Guerra Fria.

\section{O BRASIL E OS ESTADOS UNIDOS NO CONTEXTO DA AFP: DIVERGÊNCIAS POLÍTICAS CRESCENTES E $O$ PAPEL DA PROPAGANDA CULTURAL}

Um dos primeiros aspectos a serem ressaltados sobre a temática de cooperação regional é que, a despeito de sua retórica eloquente em favor de uma parceria e do interesse específico em trabalhar com o Brasil, a administração Kennedy nunca superou as fortes suspeitas sobre supostos objetivos escusos do governo Goulart, tendendo sempre a interpretar as ações do presidente brasileiro sob o prisma ideológico da Guerra Fria. Assim, desde os altos funcionários até representantes locais do governo de Washington, estes tendiam, em linhas gerais, a ver o Brasil com grande interesse, mas, ao mesmo tempo, com grande suspeição.

O interesse derivava da percepção de que o país detinha o potencial de influenciar os destinos do continente, em benefício ou em detrimento dos interesses dos Estados Unidos na região. O Brasil receberia, portanto, grande atenção nos

\footnotetext{
${ }^{1}$ Ideologia definida como "uma forma específica de consciência social, materialmente ancorada e sustentada". Ver Mészáros (2004, p. 65).

2 Articulamos as categorias analíticas gramscianas "sociedade civil" e "aparelhos privados de hegemonia", bem como a marxista "totalidade". É-nos especialmente cara a categoria "aparelhos privados de hegemonia", que define, entre os instrumentos culturais de suporte à construção de consenso na sociedade civil, o papel desempenhado pelas atividades editoriais em geral (editoras, revistas, jornais, boletins). Ver Gramsci (2001) e Coutinho (2011).
} 
primeiros anos da AFP, conquanto, em linhas gerais, esses esforços não tenham produzido os objetivos desejados (TOWNSEND, 1982; TAFFET, 2007). Por sua vez, a suspeição se embasava no retrospecto político de João Goulart, cuja ascensão se dera nos moldes da política clientelista-populista de Vargas, de quem fora ministro do trabalho no início dos anos $1950,{ }^{3}$ e das propostas nacional-desenvolvimentistas de seu governo, cujos elementos definiriam as leituras, sempre críticas, de diplomatas e emissários do governo estadunidense, dificultando, assim, a plena aceitação das políticas do governo brasileiro dos primeiros anos da década de 1960.

No âmbito econômico, o desacordo primordial entre os governos Kennedy e Goulart estava basicamente no modelo de desenvolvimento almejado por ambos para o Brasil. Herdeiro do nacional-desenvolvimentismo varguista e ancorado nas pesquisas cepalinas, o governo Goulart queria reestruturar as bases do desenvolvimento nacional alargando a presença do Estado no financiamento do desenvolvimento, acelerando a industrialização pela inversão de exportações, estabelecendo regramento à circulação de capital estrangeiro e remodelando o comércio exterior de forma a equilibrar a balança de pagamentos do país. Por sua vez, o governo Kennedy, comprometido com os interesses do capital privado e com a posição hegemônica dos Estados Unidos, deveria conduzir sua política externa de modo a facilitar a manutenção da América Latina como um mercado vantajoso ao capital privado de seu país, fechando a região às possíveis diversificações comerciais e ideológicas advindas do bloco socialista.

No âmbito político, a abertura do governo Goulart à inclusão das pautas populares por transformações na estrutura social do país - as reformas de base desagradou tanto aos setores nacionais mais conservadores quanto aos investidores internacionais, o que levou o governo Kennedy a atuar, de maneira consistente e continuada, para influenciar a cena política e enfraquecer o governo Goulart. Isso se deu de forma mais clara em especial a partir de 1962, quando, nas eleições congressuais de outubro, a Agência de Inteligência dos Estados Unidos (CIA) gastou cerca de 5 milhões de dólares para financiar as campanhas de candidatos a 15 cadeiras no Senado, 8 governos estaduais, 250 cadeiras federais e 600 vagas para as legislaturas estaduais (LEACOCK, 1990).

Com os mesmos objetivos, a administração Kennedy também buscou redesenhar o mapa do movimento sindical brasileiro e latino-americano, sobretudo com a nova arma da Guerra Fria: o Instituto Americano de Desenvolvimento do Trabalho Livre (AIFLD, sigla em inglês). Fundada pela Federação Americana do Trabalho (AFL), no fim de 1961, a missão do AIFLD era combater a dita ameaça de infiltração castrista e o eventual controle de importantes movimentos trabalhistas na América Latina. De modo efetivo, entre 1962 e 1967, a AIFLD recebeu 15,4 milhões de dólares, isto é, 89\% de seu orçamento, por meio de fundos diretamente ligados à AFP. No Brasil, o AIFLD instruiu os líderes sindicais sobre como organizar greves e manifestações contra o governo nacional, e a organização acabou enviando dez brasileiros para treinamento especial no exterior em técnicas de desestabilização (RABE, 1999; CORREA, 2017).

Ainda de acordo com a linha da interferência política e econômica, o governo Kennedy se comprometeu a subscrever um esforço conjunto para desenvolver o Nordeste brasileiro. Uma parte disso decorria de um clamor na opinião pública dos Estados Unidos, que via a região como uma das mais carentes de atenção. Grande

\footnotetext{
${ }^{3}$ Detalhes sobre essas questões podem ser encontrados em Skidmore (2010).
} 
parte, porém, decorreu de uma série de artigos de Tad Szulc, colunista do New York Times, que alertara seus leitores de que as condições de pobreza e injustiças sociais no Nordeste provocavam uma crescente consciência política nas massas. George McGovern, diretor da Alimento para a Paz (Food for Peace), foi um dos vários funcionários de alto escalão dos Estados Unidos que responderam aos relatos de Szulc ao visitar o Nordeste em outubro de 1961, juntamente como o então influente diplomata Merwin Bohan, a fim de conduzir uma análise para a Agência de Cooperação para o Desenvolvimento Internacional (USAID, como é mencionada no Brasil). Não obstante nunca tenha sido totalmente implementado, o Relatório Bohan, concluído em fevereiro de 1962, foi a base para a proposta de assistência dos Estados Unidos ao Nordeste do Brasil sob a AFP (TOWNSEND, 1982).

Malgrado a proposta de fortalecimento de laços e projetos em comum em prol do desenvolvimento do Nordeste, a cooperação entre Estados Unidos e Brasil foi inviabilizada ao longo dos anos finais do governo Goulart, resultando na aproximação da administração estadunidense aos interesses das oligarquias agrárias regionais e financiando, pois, projetos que tivessem efeitos imediatos para minar o apelo dos povos agricultores por reforma agrária, em vez de viabilizar um crescimento econômico de longo prazo, como defendido pelo prestigiado - mas, ainda assim, visto como muito próximo dos interesses comunistas locais - economista Celso Furtado, idealizador e então número 1 da Superintendência do Desenvolvimento do Nordeste (Sudene).

No sentido de refletir as frustrações recíprocas entre os governos dos dois países, as crescentes dificuldades de Goulart em implementar o acordo de estabilização econômica assinado entre o ministro das finanças do Brasil, Santiago Dantas, e David Bell, administrator da USAID ao longo de 1963, complicaram sobremaneira a parceria, levando o governo de Washington a suspender toda a assistência econômica ao governo brasileiro (LEWINSON; ONIS, 1972). No mesmo sentido, e como demonstração final do forte viés ideológico da condução da Aliança no Brasil, em flagrante contradição com os valores professados pelo mesmo programa, logo após o golpe de 1964, os Estados Unidos forneceriam uma enorme assistência econômica ao Brasil - estimados em 1,6 bilhão de dólares, entre 1964 e 1968, somente em recursos bilaterais -, valores que certamente desempenharam um papel, na sua ausência, em desestabilizar os momentos finais do governo Goulart (ADAMS, 2000).

No que tange a outros meios de encaminhamento das políticas de diplomacia cultural da Aliança, a agência que desempenhou papel-chave na promoção de visões, valores e interesses dos norte-americanos durante a Guerra Fria foi a Agência de Informação dos Estados Unidos (USIA), criada pelo presidente Eisenhower para "intensificar os esforços de explicar ao mundo" por que o país era uma "nação merecedora de defesa, emulação e vitória no contexto da Guerra Fria" (BELMONTE, 2008 , p. 49). Segundo essa lógica, e buscando atingir esses e outros objetivos, por meio de publicações, transmissões de rádio, exibição de filmes e outros métodos, propagandistas ianques procuraram elaborar comparações entre governos democráticos e comunistas, enunciando uma visão poderosa da liberdade sobre a qual repousava toda a ofensiva ideológica dos Estados Unidos contra o comunismo.

Assim, ao longo das décadas de 1950 e, sobretudo, de 1960, a USIA, suas afiliadas em todo o mundo e o Serviço de Informação dos Estados Unidos (USIS) foram encarregados de tentar influenciar a opinião pública local divulgando imagens favoráveis aos país de variadas formas - desde publicações, programas de rádio, filmes e programas de TV, visitas artísticas e acadêmicas, intercâmbios culturais, até 
apresentações dirigidas a grupos de interesse e associações públicas, bem como a uma variedade de instituições governamentais. Dois aspectos merecem destaque em relação à atividade da USIA. Em primeiro lugar, o nível de sofisticação do trabalho promovido, que aliava informação, propaganda e pesquisas de opinião pública às mais modernas ferramentas gráficas, artísticas e tecnológicas. Em segundo lugar, a ampla gama de diferentes atores sociais que essas diferentes atividades buscavam alcançar e influenciar sob os propósitos da AFP (CULL, 2008; DIZARD, 2004).

De modo geral, os escritórios do USIS estavam localizados nas agências diplomáticas dos Estados Unidos, como embaixadas e consulados. No Brasil, cidades importantes, como São Paulo, Rio de Janeiro, Belo Horizonte, Belém, Salvador, Recife, Curitiba e Porto Alegre, tinham unidades de serviços do USIS, incluindo bibliotecas e os ainda mais populares, nos anos 1950, Centros Binacionais, nos quais cursos de inglês eram ministrados e eventos comemorativos das realizações culturais dos Estados Unidos eram realizados. No início dos anos 1960, o Brasil era o país do mundo com o maior número de Centros Binacionais, num total de 64 em diversas cidades, incluindo algumas de médio porte, como Araraquara e Bento Gonçalves. ${ }^{4}$

A agência era responsável ainda pela realização de pesquisas de opinião entre diferentes segmentos da população sobre múltiplos tópicos e questões, em particular os relacionados à imagem dos Estados Unidos na região vis-à-vis à do bloco comunista, entre outros. Também foram realizadas pesquisas sobre questões políticas internas, como o apoio a importantes personalidades políticas, como Juscelino Kubitschek e João Goulart, por exemplo, assim como sobre assuntos tidos como controversos, como o papel do capital estrangeiro, a melhor forma de promover a reforma agrária etc. Tais avaliações se tornaram mais frequentes, bem financiadas e sofisticadas com o passar do tempo, graças ao clima político doméstico e à crescente assertividade do governo Kennedy na região, e no Brasil em particular, conforme detalharemos nas próximas seções.

\section{A AGENDA DE PROMOÇÃO DE POLÍTICAS CULTURAIS DA AFP: DEFINIÇÕES E ESTRATÉGIAS}

Em 1962, o governo Kennedy deu forma ao órgão que rapidamente se transformaria no mais importante centro de decisões de política externa direcionada à América Latina: o Comitê de Políticas para a América Latina (LAPC). Órgão centralizador para a coordenação de políticas para a região, o LAPC era composto por representantes de diversas agências do governo: USIA, CIA, USAID, Gabinete de Assuntos Interamericanos, Gabinete de Inteligência e Pesquisa, Departamento de Defesa e Casa Branca. Esse Comitê misto se dedicou a tratar das mais variadas questões que envolviam políticas para a região, dos problemas rotineiros até os definidos como de "segurança nacional", incluindo estratégias de ação ideológica para a AFP.

\footnotetext{
${ }^{4}$ National Archives and Records Administration/NARA, RG 306, Declassified NN3-306-02-003, General Records of the United States Information Agency, Office of Administration; Historical Collection, Murray Lawson History Card Files Series. Sobre o papel da Usia no Brasil, ver também Santomauro (2015).
} 
À USIA coube aproximar sua missão dos objetivos específicos postos pela Aliança. Ainda que, em essência, a missão da agência continuasse exatamente a mesma formulada em sua criação, em 1953, isto é, tornar os objetivos e as ações da política externa um valor universal e compartilhado de modo consensual entre todos os povos do "mundo livre", algumas mudanças operacionais foram implementadas. Tentava-se cada vez mais trabalhar em maior sintonia com a USAID, a recém-criada agência para viabilização da Aliança; aumentar o número de parcerias locais, de forma a ampliar o alcance de suas atividades; contar com aliados influentes e conhecidos do público para, por intermédio deles, disseminar informações e opiniões positivas acerca das políticas estadunidenses para a região. Editoras, universidades, institutos de pesquisa, intelectuais e jornalistas formaram a base da rede de trabalho por toda a América Latina. Só no campo editorial, entre os anos de 1960 e 1972, o programa produziu, traduziu e distribuiu 2.637 títulos e 21.144.451 cópias nos países da região. ${ }^{5}$ No Brasil, o programa contou com a participação de mais de sessenta editoras (OLIVEIRA, 2013) e um vasto número de profissionais ligados ao campo da edição de livros e revistas, professores, escritores, jornalistas, bem como universidades e centros de pesquisa. O programa produziu e distribuiu cerca de 878 títulos e 7.848.200 de cópias no mesmo período. ${ }^{6}$

Escritos, em sua grande maioria, por autores estadunidenses, tais livros foram muitas vezes encomendados pela USIA a fim de apresentar o tom e o argumento sob medida aos intentos ideológicos. Após publicados, as obras eram "trabalhadas" num circuito apropriado de legitimação: resenhas críticas positivas, publicidade aliada a figuras públicas do meio acadêmico e político, anúncios em revistas e jornais, presença em listas de "mais vendidos" em cadernos de cultura dos principais jornais do país. Não menos importante, procurava-se influenciar diretores de escolas de ensino médio e de faculdades ou departamentos universitários a adotarem os livros como leitura obrigatória em seus programas de ensino.

Assim compreendida, a ação editorial planejada e executada pela USIA, com a colaboração de vários outros setores de governo e iniciativa privada dos Estados Unidos e da América Latina - por exemplo, editoras, intelectuais e instituições de ensino e pesquisa -, se revelou ideologicamente comprometida com uma específica produção e circulação de conhecimento durante a Guerra Fria, cujo objetivo foi manter e fortalecer a hegemonia estadunidense associada e ancorada numa elite local interessada.

Em memorando oficial de 5 de julho de 1961 encaminhado a Adolf Berle, então consultor para o Departamento de Estado, John Mcknight, diretor assistente para a América Latina da USIA, fazia um balanço da atuação da agência na região. Segundo sua avaliação, havia necessidade de efetivar uma expansão racional de propaganda, com o objetivo explícito de conter o que então era chamado de "castrismo", e de reforçar a ideia de que a presença dos Estados Unidos seria mais benéfica para a região. Ele indicava ainda os alvos prioritários de tais atividades - em especial, estudantes e trabalhadores, com ênfase maior nos das zonas rurais dos países da região.

Dentro desse contexto e segundo essa lógica, a produção editorial da USIA era vista como fundamental. Mas, segundo Mcknight, era preciso corrigir algumas

\footnotetext{
${ }^{5}$ Books Published Abroad (NARA, 1966-1999, BOX 2).

${ }^{6}$ Books Published Abroad (NARA, 1966-1999, BOX 2).
} 
deficiências. Como exemplo, os panfletos produzidos de forma local, embora em quantidade significativa - consumiam cerca de 700 mil dólares do orçamento da USIS - e corretamente direcionados aos grupos-alvos, dando suporte aos objetivos estratégicos da política externa de Washington, não gastavam todos os recursos alocados para a atividade. Outro gap identificado era que somente sete ou oito postos USIS ofereciam periódicos para estudantes e trabalhadores, além de não produzir publicações para distribuição entre intelectuais. A mesma análise entendia que havia espaço para a publicação de revistas e que os postos USIS apresentavam eficiência no que dizia respeito à inserção de notícias e artigos em jornais, revistas, rádios e demais órgãos de comunicação de massa, mas que, diante da necessidade de um combate mais acirrado aos "jornais comunistas ou simpatizantes", o orçamento para impressos e publicações deveria aumentar. Mcknight expunha a cifra que julgava necessária para a realização dos objetivos: 5 milhões de dólares. ${ }^{7}$

A mesma preocupação se dava em relação à publicação de livros, que Mcknight não incluiu na análise sobre impressos em geral. Segundo sua informação, ao longo do ano fiscal encerrado em 30 de junho de 1961 - que cobria, portanto, o período de julho de 1960 a junho de 1961 -, os postos USIS haviam patrocinado a produção de menos de 500 mil livros - 65 títulos, entre espanhol e português -, a um custo aproximado de 155 mil dólares. Considerava um número baixo e recomendava triplicá-lo. Acreditava-se, apesar dos problemas de distribuição e de analfabetismo, que o livro seria um meio eficiente para influenciar estudantes e que o programa mereceria um significativo incremento orçamentário. Afirmava-se, de modo concreto:

Ao desenvolver um programa de publicações de livros maximizado para a América Latina, deve-se levar em conta o fato de que existe um alto grau de analfabetismo e o público potencial para livros é, relativamente falando, muito menor do que nos EUA. No entanto, programa realista compreendendo livros didáticos, seria executado em uma base anual para cerca de US\$4.300.000 (permitindo um acúmulo de três anos) (NARA, 1961-1963. BOX 1).

A atenção do governo Kennedy para reformular e ampliar o programa editorial da USIA (impressos, notícias e livros) foi se adensando ao longo do primeiro ano de seu governo, conforme indicam os documentos analisados. Em 7 de dezembro de 1961, ocorreu uma reunião entre o Departamento de Estado e a USIA, representados, respectivamente, por Philip $\mathrm{H}$. Coombs e Edward Murrow, ${ }^{8}$ em que concordavam com a necessidade de criação de um grupo interagências para coordenação dos trabalhos relacionados à publicação e à distribuição de livros e materiais impressos na América Latina, articulados com os propósitos da AFP.

A partir disso, uma série de novos estudos foram solicitados. Num deles, Mr. Wilbur P. Chase, da American Republics Administration (ARA), informa, em memorando

\footnotetext{
${ }^{7}$ As cifras obtidas nos documentos aqui analisados não passaram por atualização monetária e refletem os valores correspondentes à época.

${ }^{8}$ Respectivamente: Assistant Secretary of State for Educational and Cultural Affairs, 23 de março de 1961 a 4 de junho de 1962; Director of USIA, de 1961 a 1965. https://history.state.gov/departmenthistory/ people/coombs-philip-hall. Acesso em: 27 jun. 2018.
} 
de $1^{\circ}$ de fevereiro de 1962, que the fora solicitado um levantamento sobre o que estava sendo feito à época, já sob coordenação interagências, para incrementar a tradução de livros em espanhol e português para latino-americanos. Sua conclusão era que ainda havia desencontros, mas que o grupo interagências era competente e trabalhava para eliminar as falhas. O principal problema, entretanto, residia no fato de que os esforços do programa de livros do governo dos Estados Unidos e de seus parceiros privados estavam muito aquém de seu potencial, isto é, havia um book gap.

Para Chase, o trabalho mais efetivo neste campo até então fora realizado pela USIA. No ano fiscal de 1960, a agência, utilizando editoras de Rio de Janeiro, Cidade do México e Buenos Aires, distribuiu mais de 3,5 milhões de cópias de títulos na América Latina. No ano fiscal de 1961, teria distribuído 400 mil cópias de 70 títulos, e, para o ano fiscal de 1963, estimava 900 mil cópias de 100 títulos. No ano seguinte, o programa de livros da USAID operou com um orçamento de 35 mil dólares, com expectativa de expansão de recursos nos anos seguintes (NARA, 1961-1963. BOX 6).

Explicitando preocupação semelhante, Dean Rusk, ${ }^{9}$ tratando do programa de livros para a América Latina, enviou um memorando confidencial, em 21 de maio de 1962, aos representantes da USAID, Mr. Hamilton; da USIA, Mr. Murrow; da Secretaria de Educação e Assuntos Culturais (CU), Mr. Battle, e da ARA, Mr. Marin. Segundo o chanceler estadunidense, o presidente Kennedy achava o programa inadequado diante da sua importância no combate à ofensiva comunista e que os esforços nesse campo deveriam ser levados conjuntamente pelas agências citadas - USAID, USIA, CU, ARA. De acordo com essa visão, seria necessário integrar não só os esforços das agências na produção de livros de baixo custo, mas também de todos os setores privados na América Latina e dos Estados Unidos. Estimava-se provisoriamente um valor entre 5 e 7 milhões de dólares por ano de investimento por parte do governo de Washington. O presidente Kennedy esperava que ao menos 5 milhões de dólares poderiam ser disponibilizados por fundos no ano fiscal de 1963 (FY63 funds).

O documento solicitava também que o chefe assistente da Secretaria de Estado para os Assuntos Interamericanos, Mr. Morales-Carrion, se encarregasse de coordenar um trabalho cooperativo entre a USAID e a USIA cobrindo todas as facetas do programa de produção de livros. Esse trabalho coordenado poderia incluir, mas não ser limitado a: maximizar a expansão do planejamento para o ano fiscal de 1963, selecionando, traduzindo, produzindo e distribuindo livros sob o programa de livros da USIA e da USAID; um programa regional para fornecer assistência técnica e financeira a fim de fortalecer uma indústria latino-americana de publicação e distribuição de livros de baixo custo; passos para encorajar textos e livros escritos por latino-americanos para distribuição em larga escala para latino-americanos; maior uso da indústria de livros em espanhol no programa de livros; passos para incrementar a contribuição de editores latino-americanos na solução de gaps para o livro latino-americano; um programa interamericano por meio do qual um grupo formado por líderes e intelectuais latino-americanos pudessem selecionar, por ano, 25 títulos escritos por latino-americanos e outros autores ocidentais que melhor exemplificassem e reforçassem os objetivos filosóficos da Aliança; um programa interamericano coordenado para a produção massiva de livros didáticos a serem usados em todas as escolas primárias e secundárias da América Latina; um programa para selecionar e produzir livros para

\footnotetext{
${ }^{9}$ Secretário de Estado dos governos John Kennedy e Lyndon Johnson.
} 
crianças; um programa para a rápida expansão de produção de livros científicos e tecnológicos a baixo custo, usando o melhor da literatura científica produzida no mundo ocidental; uso dos serviços e da experiência de órgãos regionais e internacionais, como a Organização dos Estados Americanos (OEA), em conexão com o acima exposto. ${ }^{10}$

Inspirado nesses diagnósticos ambiciosos, bem como em reuniões e discussões entre as agências, o Departamento de Estado e a Casa Branca parecem ter elaborado uma proposta de ação cultural da AFP para o ano fiscal de 1963. O documento intitulado An Alliance for Progress Breakthrough Program on Educational, Scientific, and Cultural Development, de 26 de fevereiro de 1962, definia novas diretrizes e um orçamento maior (155,5 milhões de dólares) para desenvolver lideranças no planejamento e na administração educacional, criar centros de excelência em educação superior, lançar um programa inovador em educação rural para todos os grupos etários, estabelecer um programa inovador em educação urbana para todos os grupos etários, fortalecer o currículo de ciência, expandir o ensino da língua inglesa, acelerar a construção de escolas, produzir textos e livros a baixo custo e fortalecer intercâmbios culturais e acadêmicos. ${ }^{11}$

De igual modo, com base no mesmo documento, considerava ser imprescindível um esforço concentrado nas áreas de cultura, ciência e educação, com a adesão coordenada de agências e departamentos governamentais, como USIA, USAID, CU, Fundação Nacional da Ciência (NSF), Institutos Nacionais de Saúde $(\mathrm{NIH})$, Agência Espacial dos Estados Unidos (Nasa) e Defesa. Ressaltava-se ainda a relevância de agências e entidades privadas, assim como fundações e universidades estadunidenses, na consecução desses objetivos. Por fim, afirmava-se que "se executado vigorosamente, este programa manterá a promessa de produzir o mais avançado front em educação, ciência e cultura com consequências econômicas, sociais e políticas de longo alcance", ${ }^{12}$ isto é, levando aos desejados desenvolvimentos econômico, social e político na região latino-americana.

A viabilidade de uma proposta dessa magnitude exigia uma ampla gama de ações especificas, como um estudo sobre a melhor maneira de financiar o programa e recrutar pessoas hábeis para o staff da USAID em Washington. De fato, a partir de então, todos os oficiais de cultura e educação da USIA, da USAID e do Estado seriam levados a Washington para uma conferência de duas a três semanas, a fim de serem apresentados às políticas e aos conceitos da nova administração e examinar sua aplicabilidade e viabilidade, determinando os passos práticos para pô-lo em ação.

Da mesma forma, iniciou-se uma vasta consulta junto a fundações privadas, universidades e outras organizações, incluindo a OEA com os mesmos objetivos. Essas organizações seriam consultadas sobre a possibilidade de assumirem novas responsabilidades na operacionalidade de uma grande parte das novas iniciativas, de maneira a minimizar o financiamento sob responsabilidade das agências federais. Além disso, seria necessário combinar mais os esforços entre a estrutura governamental e privada dos Estados Unidos com as atividades de governos e entidades latino-

\footnotetext{
${ }^{10}$ Directive on Books for Latin America, Dean Rusk (NARA, 1961-1963. BOX 6).

${ }^{11}$ An Alliance for Progress Breakthrough Program on Educational, Scientific, and Cultural Development (NARA, 1961-1963. BOX 7).

${ }^{12}$ An Alliance for Progress Breakthrough Program on Educational, Scientific, and Cultural Development (NARA, 1961-1963. BOX 7).
} 
-americanas, elaborando projetos em comum, procurando interferir em suas políticas educacionais e no preparo de livros didáticos. ${ }^{13}$

Como apontado, as intenções declaradas pelo governo Kennedy nesses documentos nos informam de sua disposição em fazer com que a Aliança caminhasse sobre o tripé das forças conjugadas entre ações econômicas, políticas e culturais. Não se tratava de uma inovação propriamente dita. Esforços empregados pelos governos dos Estados Unidos (pré e pós-Kennedy) para interferir culturalmente na América Latina foram um recurso recorrente nas relações estabelecidas com a América Latina - mas não só com ela. Basta lembrar programas como o Comitê de Informação Pública (CPI) ou as atividades culturais realizadas por meio da chamada política da boa-vizinhança sob o comando de Nelson Rockfeller (TOTTA, 2014; MOURA, 2014; SANTOMAURO, 2015; VALIM, 2017).

Sob a égide da AFP, contudo, a novidade parece ser o preparo da estrutura governamental para agir de forma conjunta entre si e com organizações privadas em prol de uma ação coordenada, maximizada e orientada para um mesmo fim, como os documentos demonstram. De fato, o governo Kennedy aprofundou o entendimento demonstrado pelo governo Truman - e seguido por Eisenhower - sobre serem os trabalhos de influência cultural uma condição inconteste na conquista e na manutenção da hegemonia político-econômica, como aqui apontado.

\section{USIA-USAID E A POLÍTICA EDITORIAL PARA O BRASIL: PROMOVENDO O CAPITALISMO ESTADUNIDENSE}

Influenciar os debates sobre desenvolvimentismo era condição sine qua non para o sucesso da AFP, e o programa editorial coordenado pela equipe LAPC via esse assunto como essencial. O nacionalismo que acompanhou as políticas e os debates desenvolvimentistas na América Latina se tornou um enorme empecilho para o programa de segurança e desenvolvimento dos Estados Unidos, que os governos de Truman a Kennedy tentaram controlar, mas não sem enfrentar resistências e, algumas vezes, derrotas. ${ }^{14}$

As teorias que alimentaram as propostas nacional-desenvolvimentistas de Estado eram fornecidas pela Comissão Econômica para a América Latina e o Caribe (Cepal) e, no caso específico do Brasil, pelo Instituto Superior de Estudos Brasileiros (Iseb). ${ }^{15} \mathrm{~A}$ Teoria da Dependência se tornou, à época, o arcabouço teórico de grande relevância para os debates sobre desenvolvimento entre os países latino-americanos. Aos Estados Unidos coube, como contra-ataque, a utilização à exaustão das teorias do liberalismo e do neoliberalismo econômicos. Por sua vez, o suporte teórico realmente adequado aos debates a respeito do desenvolvimentismo direcionados aos países

\footnotetext{
${ }^{13}$ An Alliance for Progress Breakthrough Program on Educational, Scientific, and Cultural Development (NARA, 1961-1963. BOX 7)

${ }^{14}$ A bibliografia sobre desenvolvimentismo, política externa brasileira e sua relação com os Estados Unidos é extensa. Para este artigo, as referências utilizadas foram Bielschowsky (1988), loris (2017), Vizentini (2004) e Haines (1989).

${ }^{15}$ Segundo Motta (2014, p. 115, nota 8), o Departamento de Estado pressionou o governo brasileiro a cortar as verbas do ISEB já em 1960.
} 
subdesenvolvidos e de acordo com os interesses estadunidenses teria substrato mais direto ao conjunto de obras ligadas às chamadas Teorias da Modernização. ${ }^{16}$

Rejeitando o viés mais crítico formulado pelos autores latino-americanos, sobretudo ligados às matrizes dependentistas e marxistas, o projeto editorial da AFP deveria ser capaz de disseminar ao máximo as teorias da modernização, que entendiam que a trajetória histórica do desenvolvimento dos Estados Unidos poderia ser, de maneira simplista e linear, implementada na América Latina. Ao mesmo tempo, a ação política da Aliança deveria ser capaz, por sua vez, de isolar e expurgar dos governos latino-americanos a presença dos teóricos cepalinos ou os políticos a eles ligados.

Para a ação editorial da Aliança, a seleção adequada de parceiros era fundamental. Além das editoras e de jornais e revistas, a aproximação a instituições acadêmicas, intelectuais e institutos de pesquisa ideologicamente afinados eram essenciais por dois motivos: para ampliar o alcance da posição estadunidense no debate e para possibilitar o encobrimento de suas ações. Os programas de ajuda técnica da USAID foram o guarda-chuva ideal para aglutinar universidades e centros de pesquisa, envolvendo-as em análises e publicações voltadas ao seu escopo de "ajuda". Agricultura, educação, saúde, planejamento familiar, administração e administração pública foram os principais temas da atuação editorial da USAID em parcerias com editoras e universidades ${ }^{17}$. As escolas de administração da Fundação Getulio Vargas (FGV), da Universidade Federal do Rio Grande do Sul (UFRGS), da Universidade Federal de Viçosa (UFV), da Universidade Federal Rural do Rio de Janeiro (UFRRJ), da Universidade Federal de Minas Gerais (UFMG), entre outras, foram beneficiadas por acordos e repasses de verbas que atenderam desde a ampliação de estrutura física - construção de prédios e laboratórios - até a contratação de professores visitantes dos Estados Unidos e a doação e/ou subsídio para a publicação de livros (MOTTA, 2014).

Além de universidades e centros de pesquisa, a USAID fez uso de diversas parcerias para a execução de seu programa editorial, utilizando-se largamente da Franklin Book Programs, ${ }^{18}$ cuja ação no Brasil começou a se dar a partir de 1964. A Franklin Book Programs funcionava como uma intermediária entre a USAID e as editoras que recebiam os subsídios para a publicação dos livros. A lógica era a mesma empregada pela USIA, inclusive compartilhando as mesmas editoras. A USIA, em paralelo, manteve seu esquema de parcerias, apenas tratando de aumentá-lo.

Em relatório encaminhado por Arturo Morales-Moscoso, da ARA, para o secretário de Estado, em 4 de dezembro de 1963, o programa de livros da Aliança sob coordenação do LAPC havia demonstrado bons resultados. Morales elogiou o trabalho conjunto das duas agências e o fato de a USAID ter, enfim, uma equipe

\footnotetext{
${ }^{16} \mathrm{~A}$ história de como a teoria se tornou o principal marco da disputa ideológica travada pelos Estados Unidos está em Gilman, e não será nosso objetivo aprofundá-la aqui. Ver Gilman (2003).

${ }^{17}$ Nessas áreas de conhecimento, a USAID patrocinou diversas pesquisas realizadas por universidades e centros de pesquisas brasileiros.

${ }^{18}$ Fundada em 1952 e financiada pela Usia, a Franklin Book Programs foi uma entidade sem fins lucrativos voltada para a publicação e a distribuição de livros norte-americanos no exterior, especialmente em regiões por ela consideradas atrasadas e/ou em desenvolvimento, como o Oriente Médio e a América Latina. Atuou por 26 anos e em 28 línguas, em vários países, entre eles o Brasil. Ver http://findingaids. princeton.edu/collections/MC057/\#description.
} 
preparada para o programa de livros. A cooperação e a coordenação USIA-USAID se tornaram efetivas, segundo sua análise, sendo demonstradas concretamente nas operações de campo na Cidade do México e no Rio de Janeiro, assim como no acordo entre ambas para definir responsabilidades e áreas de atuação temática.

Conforme seu relatório, a USAID produzira 6 títulos, e outros 25 ainda estavam em processo. Dos 200 mil dólares, 160 mil foram usados na contratação de editoras e 40 mil foram destinados a títulos específicos de interesse da FGV, sendo 15 títulos sobre desenvolvimento econômico. ${ }^{19} \mathrm{~A}$ USIA, por sua vez, usou 1,4 milhão de dólares no ano fiscal de 1963. Foram contratados 332 novos títulos, apresentando um total de 3.629 .750 cópias.

A dedicação da USIA para a publicação e a distribuição de livros com temática sobre capitalismo e sistema econômico estadunidense, entretanto, data do início de suas atividades editorias, no Brasil inclusive, como comprova a lista elaborada pelo diretor assistente para a América Latina, Hewson A. Ryan, enviada à LAPC em 28 de agosto de 1962. A lista de 54 títulos reúne publicações entre 1954 e 1962.

Acompanhando a lista e o ano de publicação, é possível iniciar uma reflexão sobre a estratégia editorial para travar a batalha ideológica na qual o programa de livros estava inserido. Dos 54 títulos publicados no período entre 1954 e 1962, os temas podem ser assim organizados: até 1960, os livros variavam entre o sistema capitalista, especialmente o dos Estados Unidos, com ênfase no capital privado, negócios e comércio. ${ }^{20}$ A partir de 1961, os livros começaram a abordar estratégias e etapas de desenvolvimento, subdesenvolvimento, bem como desenvolvimento econômico para a América Latina. Nessa fase, livros de Rostow (1960) e Hirschman (1958), autores ligados à Teoria da Modernização, foram publicados. Em documento produzido pelo Serviço do Centro de Informações, a USIA informa a um comitê não especificado a lista de livros que a agência pretendia publicar na América Latina para o ano fiscal de 1963, em que o tema economia do desenvolvimento ocupava alta prioridade. Nela constam 33 títulos sobre o assunto, ${ }^{21}$ incluindo a AFP. ${ }^{22}$

A orientação da USIA para que o programa de livros enfatizasse os temas sobre economia é mantida para o ano de 1964. Em memorando de 6 de abril desse

\footnotetext{
${ }^{19}$ Summary of Second Status Report on the Latin American Book Program - FY 1963 (NARA, 19611963. BOX 15).

${ }^{20}$ A razão do envio da lista era auxiliar na seleção que o LAPC estava elaborando sobre livros voltados para esse tema e evitar, assim, sobreposições. Ver: Books on US Economic System Published in Brazil (NARA, 1961-1963. Box 15).

${ }^{21}$ Ordem de prioridade, conforme documento: 1. Ciência Política e Democracia, 19 títulos; 2. Economia e Desenvolvimento Econômico, 33 títulos; 3. Comunismo em teoria e prática, 16 títulos; 4 . Política Externa dos Estados Unidos, 13 títulos; 5. Lei e Jurisprudência, 6 títulos; 6. História, 12 títulos; 7. Educação, 17 títulos; 8. Sociologia, Psicologia, Trabalho e Bem-Estar Social, 18 títulos; 9 . Filosofia, 16 títulos; 10. Livros infanto-juvenis, 20 títulos; 11. Biografias de grandes americanos, 11 títulos; 12. Cultura norte-americana, 8 títulos; 13. Vida cotidiana nos EUA, 11 títulos; 14. Clássicos da Literatura norte-americana, 16 títulos. "Inclusion of a title in this list does not necessarily mean that negotiations for translation or publication have been initiated. The list is intended simply to give the Committee an idea of the kids of books being included in the expanded USIA Latin American translation program". USIA Latin American Book Program (NARA, 1954-1968, BOX 8).

${ }^{22}$ ALLIANCE FOR PROGRESS (texts of 5 approaches by Dean Rusk, Teodoro Moscoso, José Figueres, Raul Prebisch and Milton Eisenhower). Idem.
} 
ano destinado a todos os postos USIS, os temas econômicos e políticos receberam ainda maior atenção, sendo declarados prioritários, conforme a seguinte justificativa:

Os EUA desenvolveram a economia mais poderosa e produtiva que a palavra já viu, baseada em um equilíbrio dinâmico entre negócios, trabalho e governo. Incentivos fornecem oportunidades; governo protege contra abusos e excesso de flutuação do ciclo de negócios. A economia dos EUA continua a crescer rapidamente, e não há evidências de que os soviéticos a superarão em breve ou no futuro previsível. A força e a produtividade da economia dos EUA permitem que os EUA forneçam a seus cidadãos padrões materiais e medidas de bem-estar que os comunistas só prometeram; manter a si mesma e ao mundo livre armado em um nível adequado para proteger contra todas as formas de ataque, e para fornecer ajuda substancial aos países menos desenvolvidos. [...] Benefícios sociais, sindicatos fortes, um sistema tributário progressivo, ampla propriedade de capital pela população e agências reguladoras do governo contribuem para a propriedade e o gozo generalizado da riqueza produtiva dos EUA. O sistema americano de "capitalismo com consciência" está muito mais próximo, em filosofia e prática, da socialdemocracia não-coercitiva da Europa Ocidental do que do conceito anterior do capitalismo. Apesar desse progresso, os EUA buscam oportunidades econômicas e igualdade ainda maiores para todos os seus cidadãos. ${ }^{23}$

Seguir as diretrizes estabelecidas e aprovadas pela USIA era uma obrigação dos postos USIS. Em relatório de abril de 1964 sobre o posto USIS Rio de Janeiro e o cumprimento de sua tarefa, consta que o orçamento total do posto para aquele ano fora de 2.882,111 dólares, sendo 480 mil apenas para o programa de tradução de livros.

Programa centrado no Rio de Janeiro. Posto agora trabalhando com 13 editores no Rio de Janeiro, 5 em São Paulo, 2 em Belo Horizonte e 1 em Porto Alegre.

107 títulos publicados em 1964. 155 títulos contratados no ano fiscal de 1964. Impressão totalizando 930.000 cópias.

\footnotetext{
${ }^{23}$ No original: "The US has developed the most powerful and productive economy the word has ever seen, based on a dynamic balance among business, labor, and government. Incentives provide opportunity; government protects against abuses and excess fluctuation of business cycle. The US economy continues to grow rapidly, and there is no evidence that the Soviets will overtake it soon or in the foreseeable future. The strength and productivity of the US economy permits the US to provide its people with material standards and welfare measures which the communists have only promised; to keep itself and the free world armed at a level adequate to protect against all forms of attack, and to provide substantial aid to less developed countries. [...] Social benefits, strong labor unions, a progressive tax system, broad capital ownership by the populace, and Government regulatory agencies contribute to widespread ownership and enjoyment of US productive wealth. The American system of 'capitalism with a conscience' is far closer in philosophy and practice to the non-coercive Social Democracy of Western Europe than it is to the earlier capitalism concept. Despite this progress, the US seeks still greater economic opportunity and equality for all its citizens" (NARA, 1954-1968, BOX 19, tradução nossa).
} 


\begin{abstract}
Pesquisas em livrarias nas principais cidades mostram que os livros patrocinados pelo USIS agora ultrapassam o número de livros comunistas e ultranacionalistas disponíveis para o público em geral. ${ }^{24}$
\end{abstract}

Esse relatório traz também informações sobre a atuação do posto na imprensa brasileira - manutenção contínua de aproximadamente 244 jornais em todo o país. Quase 500 jornais, revistas, boletins etc. forneceram pontos de venda para materiais, ${ }^{25}$ dentro de um grande esforço que cresceria após os eventos marcantes daquele ano.

\title{
APONTAMENTOS FINAIS: NOVAS TÁTICAS EM MEIO A VELHAS ESTRATÉGIAS E OBJETIVOS
}

A análise de parte da documentação sobre a ação editorial da USIA e da USAID, assim como os documentos produzidos pelo Departamento de Estado, indica que, embora não devidamente compreendida como fundamental no momento de sua formulação pelos policymakers dos Estados Unidos, a dimensão cultural da AFP se impôs como condição sine qua non na sua implementação.

De maneira concreta, ao mesmo tempo que o governo estadunidense continuava a manter fortes constrangimentos à autonomia econômica e à política independente das nações latino-americanas, o governo Kennedy estabelecia novos mecanismos de interferência na produção e na circulação de conhecimento locais, procurando excluir dos debates regionais teorias anticapitalistas e as de capitalismo de tipo nacionalista, buscando assim moldar uma compreensão mais efetiva sobre modelos de desenvolvimento que se encaixassem e atendessem mais claramente aos objetivos econômicos de Washington.

Fica claro também o caráter sofisticado e multidimensional do projeto de influenciar e, se necessário, controlar o caminho de desenvolvimento latino-americano por parte dos Estados Unidos no auge da Guerra Fria. Assim, de maneira planejada, sustentada e recorrendo muitas vezes ao uso de ações encobertas de promoção de uma visão específica de desenvolvimento nos moldes capitalistas e gradativamente menos reformista, o escopo da ação estadunidense se revela não só na soma de recursos financeiros, mas na amplidão de parcerias, que envolveu setores dos governos dos Estados Unidos e de países latino-americanos, assim como os setores privados de todas as nações envolvidas. Mas, apesar do alto grau de articulação e da ampla mobilização de agentes e recursos, a atuação ideológica estadunidense na América Latina não deixou de apresentar fortes ecos de um passado de hegemonia econômica e cultural no hemisfério.

\footnotetext{
${ }^{24}$ No original: "Program centered in Rio de Janeiro. Post now working with 13 publishers in Rio de Janeiro, 5 in São Paulo, 2 in Belo Horizonte and 1 in Porto Alegre. 107 titles published in 1964. 155 titles contracted in FY 1964. With printing to total 930,000 copies. Surveys in bookstores in major cities show USIS-sponsored books outnumbered the communist and ultra-nationalist books available to the general public. Brazil USIA Program Summary” (NARA, 1962-1966, BOX 2, tradução nossa).

${ }^{25}$ No original: "Continued servicing of approximately 244 newspapers throughout the country. Almost 500 newspapers, magazines, bulletins, etc. provided placement outlets for materials" (NARA, 19621966, BOX 2, tradução nossa).
} 
Não obstante os altos ideais e a retórica grandiloquente envolvendo os programas da AFP, o autointitulado parceiro do Norte continuaria a agir, em linhas gerais, segundo interesses estratégicos e vieses ideológicos típicos do contexto da Guerra Fria, realidade que impediu mais efetivas parcerias no hemisfério ocidental, em especial entre os dois maiores países da região.

\section{REFERÊNCIAS}

ADAMS, Francis. Dollar Diplomacy: United States Foreign Assistance to Latin America. London: Ashgate, 2000.

BELMONTE, Laura A. Selling the American Way: U.S propaganda and the Cold War. Philadelphia: University Pennsylvania Press, 2008.

BIELSCHOWSKY, Ricardo. Pensamento econômico brasileiro: o ciclo ideológico do desenvolvimentismo. 2. ed. Rio de Janeiro: Contraponto, 1995.

CORREA, Larissa R. Disseram que voltei americanizado: relações sindicais BrasilEstados Unidos na ditadura militar. Campinas: Editora Unicamp, 2017.

COUTINHO, Carlos N. (org.). O leitor de Gramsci. Rio de Janeiro: Civilização Brasileira, 2011.

CULL, Nicholas. The Cold War and the United States Information Agency: American propaganda and public diplomacy, 1945-1989. New York: Cambridge University Press, 2008.

DIZARD JR., Wilson P. Inventing Public Diplomacy: the story of the U.S Information Agency. Boulder: Lynne Rienner Publishers, 2004.

GILMAN, Nils. Mandarins of the future: modernization theory in Cold War America. Baltimore: Johns Hopkins University Press, 2003.

GRAMSCI, A. Cadernos do cárcere. Organização de Carlos Nelson Coutinho. Rio de Janeiro: Civilização Brasileira, 2001, v. 2.

HAINES, Gerald K. The Americanization of Brazil: a study of US Cold War diplomacy in the Third World, 1945-1954. Washington: Scholarly Resources Inc., 1989.

HIRSCHMAN, Albert. The Strategy of Economic Development. Yale Studies in Economics: 10. New Haven: Yale University Press, 1958.

IORIS, Rafael R. Qual desenvolvimento?: os debates, sentidos e lições da era desenvolvimentista. Jundiaí: Paco, 2017.

LEACOCK, Ruth. Requiem for Revolution: The United States and Brazil, 1961-1969. Kent: Kent State University Press, 1990. 
LEWINSON, Jerome; ONIS, Juan de. The Alliance that Lost its Way: A Critical Report on the Alliance for Progress. Chicago: Quadrangle Books, 1972.

MOTTA, Rodrigo Patto Sá. As universidades e o regime militar. Rio de Janeiro: Zahar, 2014.

MOURA, Gerson. Tio Sam chega ao Brasil: a penetração cultural americana. 5. ed. São Paulo: Brasiliense, 1988.

NARA, RG 306, ICS. Publication Division. Editorial Branch ca 1965-ca.1974. Book Development Files, 1954-1968, BOX 8, Folder Latin American Book Program.

NARA, RG 306, ICS. Publication Division. Editorial Branch ca 1965-ca.1974. Book Development Files, 1954-1968, BOX 19, Folder Directors quarterly meeting proposals.

NARA, Department of State. Bureau of Inter-American Affairs. Office of the Deputy Assistant Secretary. Subject Files, 1961-1963. BOX 1 Folder: Propaganda Program in LA.

NARA, Department of State. Bureau of Inter-American Affairs. Office of the Deputy Assistant Secretary. Subject Files, 1961-1963. BOX 6. Folder: Books Department of State Material.

NARA, Department of State. Bureau of Inter-American Affairs. Office of the Deputy Assistant Secretary. Subject Files, 1961-1963. BOX 7, Folder Cultural CU Activities in LA.

NARA, Department of State. Bureau of Inter-American Affairs. Office of the Deputy Assistant Secretary. Subject Files, 1961-1963. BOX 15, Folder Material $-2^{\text {nd }}$ Book Report.

NARA, RG 306, Office of Policy. Records relating to Counterinsurgency Matters, 1962-1966, BOX 2, Folder CI Brazil.

NARA, RG 306, Records Relating to the Book Program, 1966-1999. BOX 2.

OLIVEIRA, Laura. Publicar ou perecer: a Edições GRD, a política da tragédia e a campanha anticomunista no Brasil, 1956-1968. 2013. 274 p. Tese (Doutorado em História) - Departamento de História, Universidade Federal de Goiás, Goiânia, 2013.

RABE, Stephen. The most dangerous region in the world: John F. Kennedy confronts communist revolution in Latin America. Chapel Hill: University of North Carolina Press, 1999.

ROETT, Riordan. The politics of foreign aid in the Brazilian Northeast. Nashville: Vanderbilt University Press, 1972. 
ROGES, William D. The twilight struggle: The Alliance for Progress and the politics of development in Latin America. New York: Random House, 1967.

ROSTOW, Walt Whitman. The Stages of Economic Growth: A Non-Communist Manifesto. Cambridge: Cambridge University Press, 1960.

SANTOMAURO, Fernando. A atuação política da Agência de Informação dos Estados Unidos no Brasil, 1953-1964. São Paulo: Cultura Acadêmica, 2015. Formato ePub.

SCHEMAN, L. R. (ed.). The Alliance for Progress: a retrospective. New York: Praeger, 1988.

SCHLESSINGER JR., Arthur M. A thousand days: John F. Kennedy in the White House. New York: Mariner Books, 2002.

SKIDMORE, Thomas. Brasil: de Getúlio a Castello, 1930-1964. São Paulo: Companhia das Letras, 2010.

TAFFET, Jeffrey. Foreign Aid as Foreign Policy. Routledge, 2007.

TOTTA, Antonio Pedro. O amigo americano: Nelson Rockefeller e o Brasil. São Paulo: Companhia das Letras, 2014.

TOWNSEND, Joyce C. Bureaucratic politics in American decision making: impact on Brazil. Lanham, MD: University Press of America, 1982.

VALIM, Alexandre B. O triunfo da persuasão: Brasil, Estados Unidos e o cinema da Política de Boa Vizinhança durante a II Guerra Mundial. São Paulo: Alameda, 2017.

\section{NOTAS}

\section{AUTORIA}

Rafael R. Ioris: Doutor. Professor adjunto, University of Denver, History Department and Latin American Center, Josef Korbel School of International Studies, Denver, CO, Estados Unidos.

Josiane Mozer: Mestre. Doutoranda, Universidade Federal do Rio Grande do Sul, Instituto de Filosofia e Ciências Humanas, Departamento de História, Porto Alegre, RS, Brasil

\section{ENDEREÇO PARA CORRESPONDÊNCIA}

Rafael R. loris. University of Denver, 2000 E. Asbury Ave., Sturm Hall \#367, Denver, CO 80208, USA

\section{FINANCIAMENTO}

Este artigo foi financiado com bolsa do Programa de Doutorado Sanduíche no Exterior (PDSE) da Coordenação de Aperfeiçoamento de Pessoal de Nível Superior (Capes) - Edital 19/2016, Processo 88881.133642/2016-01. 


\section{APROVAÇÃO DE COMITÊ DE ÉTICA EM PESQUISA}

Não se aplica.

\section{CONFLITO DE INTERESSES}

Não houve conflito de interesses.

\section{LICENÇA DE USO}

Este artigo está licenciado sob a Licença Creative Commons CC-BY. Com essa licença você pode compartilhar, adaptar, criar para qualquer fim, desde que atribua a autoria da obra.

\section{PUBLISHER}

Universidade Federal de Santa Catarina. Programa de Pós-Graduação em História. Portal de Periódicos UFSC. As ideias expressadas neste artigo são de responsabilidade de seus autores, não representando, necessariamente, a opinião dos editores ou da universidade.

\section{EDITORES}

Alex Degan

Beatriz Mamigonian

Fábio Augusto Morales

Flávia Florentino Varella (Editora-chefe)

Tiago Kramer de Oliveira

Waldomiro Lourenço da Silva Júnior

\section{HISTÓRICO}

Recebido em: 9 de fevereiro de 2019

Aprovado em: 3 de maio de 2019

Como citar: IORIS, Rafael R.; MOZER, Josiane. Parceiros em quê? A Aliança para o Progresso

e a política editorial de modernização da América Latina no contexto da Guerra Fria. Esboços, Florianópolis, v. 26, n. 43, p. 529-548, set./dez. 2019. 